\title{
Antonin Artaud, Lettres 1937-1943
}

\section{Fabio Scotto}

\section{(2) OpenEdition}

\section{Journals}

\section{Edizione digitale}

URL: http://journals.openedition.org/studifrancesi/5422

DOI: 10.4000/studifrancesi.5422

ISSN: 2421-5856

\section{Editore}

Rosenberg \& Sellier

\section{Edizione cartacea}

Data di pubblicazione: 1 dicembre 2016

Paginazione: 562

ISSN: 0039-2944

\section{Notizia bibliografica digitale}

Fabio Scotto, «Antonin Artaud, Lettres 1937-1943 », Studi Francesi [Online], 180 (LX | III) | 2016, online dal 01 janvier 2017, consultato il 18 septembre 2020. URL : http://journals.openedition.org/ studifrancesi/5422 ; DOI : https://doi.org/10.4000/studifrancesi.5422

\section{Questo documento è stato generato automaticamente il 18 settembre 2020.}

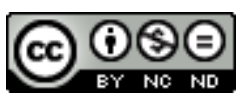

Studi Francesi è distribuita con Licenza Creative Commons Attribuzione - Non commerciale - Non opere derivate 4.0 Internazionale. 


\title{
Antonin Artaud, Lettres 1937-1943
}

\author{
Fabio Scotto
}

\section{NOTIZIA}

ANTONIN ARTAUD, Lettres 1937-1943, édition établie par Simone Malausséna, préface de Serge Malausséna, introduction d'André Gassiot, Paris, Gallimard, 2015, 490 pp.

1 È noto come nella travagliata esistenza di Antonin Artaud, tanto duramente segnata dalla malattia psichica, la scrittura epistolare abbia, dalla Correspondance avec Jacques Rivière alle Lettres écrites de Rodez, rivestito un ruolo essenziale, nel contempo rivelatorio e a suo modo catartico, se a questo termine si sottrae l'aura salvifica che per il grande scrittore, artista e drammaturgo marsigliese sarebbe fuori luogo, data l'inopportunità nel suo caso di ogni happy ending.

2 Va accolta quindi come un'ulteriore tappa conoscitiva filologicamente significativa l'edizione di un nuovo corpus di lettere inedite (alcune delle quali riprodotte anche in originale), scritte verosimilmente, afferma il nipote del poeta Serge MALAUSSÉNA nella «Préface» (pp. 9-16), nel corso dei suoi ricoveri forzati in asili psichiatrici e molte delle quali mai giunsero ai rispettivi destinatari, in quanto preventivamente sequestrate dai servizi di controllo.

3 Come spiega nella sua «Introduction» (pp. 17-27) il dottor André GASSIOT, psichiatra già primario a Rodez, che ripercorre l'evoluzione dall'Ancien Régime a oggi dell'idea d'alienato mentale nella società francese (non senza un implicito richiamo, crediamo, alla celebre Histoire de la folie à l'âge classique di Michel Foucault), queste lettere sono testimonianze del periodo più buio della vita di Artaud e non possono essere comprese se non tenendo conto del legame indissolubile fra la vita e l'opera dell'artista, il quale, sbarcato a Le Havre nel 1937, viene subito internato in quanto affetto da una psicosi delirante che lo porta a manifestare manie di persecuzione, fobie d'avvelenamento, scissioni identitarie che lo inducono a rivendicare il cognome materno Nalpas. Gassiot scandisce le varie tappe di questo calvario psichiatrico d'internamenti in vari asili diversi, fino all'approdo nel 1938 all'hôpital Sainte-Anne, solo antidoto al quale fu per 
Artaud la creazione artistico-letteraria. In seguito, il trasferimento a Ville-Évrard, dove saltuarie visite familiari mitigarono momentaneamente la penuria alimentare di cui molto ebbe a soffrire, prima dell'arrivo all'Asile de Paraire, a Rodez, nel febbraio 1943, dove rimase fino al 1946. Il clinico con acume rileva come in Artaud «nous atteignons des sommets où le génie flirte avec le délire» (p. 20) e identifica in quattro punti i tratti salienti della sua psicobiografia, ovvero la complessità dell'uomo, la sua malattia principale, l'organizzazione del suo pensiero e i suoi mezzi espressivi.

4 Il volume, che alterna lettres-pamphlets ai medici, le quali stigmatizzano la crudeltà della condizione semicarceraria cui è confinato il malato di mente, ad altre più giocate sul delirio identitario e le deformazioni nominali indirizzate a varie figure istituzionali allo scopo di denunciare violenze o abusi di varia natura subiti (in una si firma, ad esempio, Antoneo Arlanapulos, p.37, ma si rammenti che la madre di Artaud parlava correntemente greco in famiglia) e supplicare interventi in suo favore volti a liberarlo e a farlo uscire dai luoghi d'internamento, è anche un'occasione di confrontarsi con lo stile di Artaud, che ricorre ai caratteri maiuscoli come a indicare teatralmente un innalzamento dell'intensità vocale (si pensi a «J'AI UN TERRIBLE COMPTE DE SANG À RÉGLER AVEC TOUT LE MONDE», p.216), oltre che a sottolineature enfatiche che rendono più visivamente immediata e percussiva la sfera emozionale del gesto scrittorio. Ne deriva una teatralità di fondo dei testi, sorta di vibranti micro-monologhi costitutivi di un'arte quale autoterapia in risposta all'«incapacité d'être».

Correda il volume un utile ed esaustivo elenco delle «Personnes citées» (pp. 469-490). 